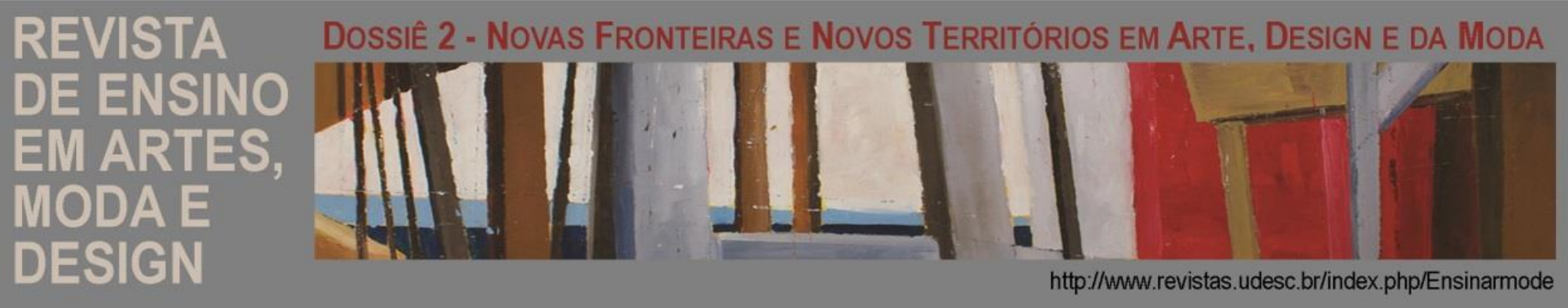

\title{
CULTURA DE COMPARTILHAMENTO EM PROCESSOS AVALIATIVOS
}

Maria Carolina Garcia ${ }^{1}$

\section{RESUMO}

Este artigo tem por objetivo analisar de que maneira o modelo de apresentação dos trabalhos de conclusão dos cursos de Design do Centro Universitário Belas Artes de São Paulo converteu-se na mostra BA Creative Collectibles. Igualmente, apresenta seu impacto a longo prazo para os egressos de Design de Moda da instituição. Para tanto, o estudo de caso considera o conceito de economia de compartilhamento desenvolvido por Gansky (2011) e o entendimento de metadesign em sistemas complexos proposto por Alão (2015) como elementos de ressignificação simbólica de processos avaliativos. Assim, observa de que maneira o BA Creative Collectibles eliminou as bancas de defesa, compostas majoritariamente por docentes, em prol de um sistema de avaliação em formato de exposição interativa, que inclui como avaliadores acadêmicos, pesquisadores e profissionais do mercado brasileiro de design. Como resultado, os estudantes tiveram acesso a distintas oportunidades de colocação profissional e foi possível observar que a força e a diversidade do ecossistema da Economia Criativa dependem de uma educação ampla e balanceada. Essa proposta desenvolve um largo espectro de caminhos para a criatividade, com forte foco em uma vida cultural ativa, na sistematização de habilidades de comunicação e na pró-atividade e caráter empreendedor do estudante. Consequentemente, os parâmetros de excelência acadêmica garantem posicionamento e visibilidade no mercado tanto para os egressos quanto para a instituição de ensino.

Palavras-chave: Trabalho de Conclusão de Curso. Método de avaliação. Metadesign. BA Creative Collectibles.

\footnotetext{
${ }^{1}$ Doutora em Comunicação e Semiótica pela PUC-SP. Head de Design do Centro Universitário Belas Artes de São Paulo.

E-mail: maria.garcia@belasartes.br | Lattes: http://lattes.cnpq.br/5136217690821399
} 


\title{
1 INTRODUÇÃO
}

Em 2016, durante a revisão e discussão periódica das matrizes curriculares dos cursos de graduação em Design de Moda, Design de Interiores, Design Gráfico e Design de Produto do Centro Universitário Belas Artes de São Paulo, observaram-se novas necessidades e demandas em relação ao padrão de qualidade e forma de avaliação dos Trabalhos de Conclusão de Curso - TCCs. Este estudo tem como objetivo geral compreender em que medida e de que maneira a experiência estética da apresentação dos trabalhos de conclusão de cursos de graduação em Design pode impulsionar a integração entre estudantes e profissionais, possivelmente incentivando o surgimento de um sistema de avaliação humanizado e participativo. Isso se dá por meio do estabelecimento de uma rede de relacionamentos orgânica, que privilegia a troca de conhecimentos entre os participantes durante todo o processo avaliativo, aproximando escola e mercado em uma mostra multidisciplinar, aberta à comunidade, nos princípios da chamada "economia de compartilhamento", ou "economia colaborativa", termo cunhado por Lisa Gansky em sua obra Mesh: Por que o Futuro dos Negócios é Compartilhar.

Como hipótese, parte-se do princípio de que, na cultura da convergência, a instituição de ensino pode eventualmente ser considerada como interface (DE WAAL, 2014) e o compartilhamento como elemento de ressignificação simbólica dos objetos e de suas funções (GANSKY, 2011; BOTSMAN e ROGERS, 2011). Paralelamente, busca-se entender os fatores que poderiam desencadear essas transformações por meio do estudo da relação entre processo avaliativo e metadesign, tendo como corpus para análise as apresentações de trabalhos de conclusão das graduações em Design do Centro Universitário Belas Artes de São Paulo, instituição de ensino superior que, há 92 anos, vem se destacando por sua capacidade em atrair a classe criativa. Precisamente, para Alão (2015, p. 127),

\begin{abstract}
quando se usam soluções colaborativas (...) quase sempre se está falando em metadesign: cria-se um serviço com recursos necessários para que os usuários possam criar soluções se utilizando deles. Num primeiro momento, pode parecer que o designer desaparece quando se usam técnicas de metadesign, ficando a responsabilidade da organização da solução por parte do usuário, mas não é este o caso. É o designer que concebe as possibilidades de interação entre usuários: como eles poderão colaborar, o que poderão criar, como deverão compartilhar arquivos, como podem se associar, como poderão colher os frutos daquilo que produzem.
\end{abstract}

Especificamente, este artigo objetiva abordar como tais parâmetros foram construídos e implementados no Bacharelado em Design de Moda, a partir da criação de uma exposição dos trabalhos, denominada BA Creative Collectibles, que reuniu todos os formandos dos cursos de Design a partir do segundo semestre de 2016, alterando de maneira significativa o formato de avaliação dos projetos 
elaborados nesta etapa de qualificação dos estudantes. O BA Creative Collectibles pode ser considerado um serviço, ou solução colaborativa no sentido mencionado por Alão (2015, p. 127), uma vez que a instituição de ensino se encarrega de reunir público qualificado em distintas esferas para interação com os formandos e seus projetos, o que permite maior abrangência dos trabalhos junto à comunidade.

Em sua primeira edição, em dezembro de 2016, o evento recebeu em torno de 2800 visitantes e 450 avaliadores de mercado, que apreciaram mais de cem projetos em dois dias de exibição. Duas edições seguiram-se à inicial, sempre no encerramento do semestre letivo, nos meses de junho e dezembro de 2017 . Na ocasião, os formandos puderam apresentar os resultados de seus estudos e potencial de inclusão na indústria da moda a expoentes do setor ${ }^{2}$. O evento resultou em ampla visibilidade para os alunos concluintes e maior integração entre academia e mercado de moda, tendo se repetido nos semestres que se seguiram, sempre com público superando a casa dos milhares de visitantes.

O foco deste artigo é apresentar e analisar esse formato diferenciado de avaliação participativa. Com adoção da metodologia de estudo de caso, o estudo contextualiza a produção do TCC na área de Design da Belas Artes e o surgimento do BA Creative Collectibles, observando como o evento passou a priorizar a importância da interação entre estudantes e distintos públicos. Na primeira etapa, apresenta-se o percurso do curso de Design de Moda para, em seguida, situá-lo em relação aos princípios qualitativos que norteiam os rankings internacionais das escolas de design. Em seguida, baseado nas demandas da classe criativa e nos princípios do metadesign, o estudo considera a mostra em si como uma estratégia de ensino-aprendizagem. "Essa distinção é importante porque desloca os objetivos do design da mostra física - dispor as peças para que o público as veja desde certa distância - ao trabalho mais exigente de captar e modelar a percepção que o público terá da exposição" (HUGHES: 2010, p. 78).

\footnotetext{
2 Estiveram presentes Lucius Vilar, pesquisador da Assintecal e stylist da revista Bloom; Renato Kherlakian, fundador das marcas Zoomp e Zapping; Eduardo Dugois, relações públicas da marca Ellus; Mareu Nitzchke, estilista e fundador da galeria Quadrado (ex diretor de criação da Havaianas); Karlla Girotto, artista plástica e fundadora da Casa do Povo; Dóris Bicudo, jornalista; Gilberto Mariot, autor da obra Fashion Law e advogado; Thays Leite Toschi, advogada fundadora da seccional de Moda da OAB-SP; empresária Alice Ferraz, fundadora do FHits; publicitária Daniela Dornellas, fundadora do Fashion Meeting e proprietária da agência WeExpand; Cadu Dantas, blogger de moda masculina; Beto Guimarães, diretor da agência Carme; Alexandra Von Bismarck, stylist; Daniela Pizetta, diretora de marketing do Shopping Iguatemi; Carina Duek, estilista; Juliana Jabour, estilista; Marcella Kanner, diretora de marketing da rede de varejo de moda Riachuelo; Leticia Veloso, sóciadiretora da Index Assessoria.
} 
Graças a esse percurso, o trabalho destaca em suas considerações finais como os resultados dos TCCs puderam ser apreciados posteriormente em destacadas feiras - entre as quais SPArte, MADE, Eco Fashion Week e Fashion Meeting, em São Paulo; Salone Satellite, em Milão; e London Fashion Week, em Londres - por meio de curadoria realizada a partir da visitação de profissionais ao BA Creative Collectibles. Nesse sentido, o estudo considera que o BA Creative Collectibles converte o sistema cíclico de processos avaliativos num sistema complexo, em virtude do que $\operatorname{ALÃO}(2015$, p. 138) caracteriza como "feedback positivo". Para o estudioso, o que designa o feedback positivo é uma variação na mesma direção do estímulo, gerando um efeito cascata, efeito manada ou efeito borboleta (como é chamado nas ciências da complexidade), observado nos resultados alcançados pelo BA Creative Collectibles, conforme veremos a seguir.

\section{APRENDIZAGEM CONTÍNUA, AVALIAÇÃO CONSTANTE}

\subsection{Moda na Belas Artes}

Para entender como e porque se estabeleceu esse percurso, é importante salientar que o Bacharelado em Design de Moda do Centro Universitário Belas Artes de São Paulo foi autorizado a funcionar, com conceito máximo, em outubro de 2000, e a primeira turma, com 23 alunos, formou-se em 2004, num contexto de ascensão da moda brasileira em âmbito global. Mais de uma década depois da implementação do curso, projeções da Associação Brasileira da Indústria Têxtil e de Confecção (ABIT) indicam que o faturamento do setor têxtil e de confecção deverá registrar crescimento de 5,5\% em 2018, alcançando $R \$ 152$ bilhões. A produção de vestuário deve aumentar $2,5 \%$, para 6,05 bilhões de peças, e a têxtil poderá avançar $4 \%$ no período, a 1,84 milhão de toneladas, apontando sua importância para a economia nacional. O Brasil é referência mundial em design de moda praia, jeanswear e homewear, tendo crescido também os segmentos de fitness e lingerie. No entanto, questões ligadas à sustentabilidade, ao progresso tecnológico e ao comportamento de consumo demandam constantes análises e adequações da formação do designer de moda.

O curso de Bacharelado em Design de Moda da Belas Artes destacou-se, ao longo dos anos, precisamente por meio de sua interação com toda a cadeia têxtil, fomentando ampla discussão das habilidades e competências e imprimindo 
agilidade para implementar mudanças na matriz curricular, de modo que o egresso pudesse galgar posições nesse acirrado e competitivo mercado. Parcerias estratégicas com fornecedores (como Lectra Systems, Swarovski Crystals, Texprima, Vicunha e Focus Têxtil), entidades setoriais (como Assintecal, Associação Brasileira de Estilistas - ABEST, Associação Brasileira de Pesquisas e Estudos em Moda - ABEPEM, Associação Brasileira da Indústria Têxtil - ABIT, Ordem dos Advogados do Brasil - OAB, setorial Moda), movimentos sociais (como Fashion Revolution Day), eventos (como São Paulo Fashion Week, Casa de Criadores, Fashion Cruise, Inspiramais, Design Week, MADE e Fashion Meeting), imprensa especializada (como as revistas Vogue Brasil, Glamour, Elle, Harper's Bazaar, L'Officiel e o portal de influenciadores digitais FHits) permitiram ampla circulação dos alunos do curso em showrooms, desfiles, fábricas e lojas. Nesse ínterim, os estudantes ganharam concursos de empresas renomadas do mercado nacional ${ }^{3}$, criando projetos com características realistas.

Essa interação com o mercado foi ampliada em 2015, 2016 e 2017, quando especialistas estrangeiros, representando o mercado internacional de moda, passaram a integrar comissões de avaliação dos trabalhos de conclusão em andamento, antes mesmo da avaliação final, para promover ajustes. Entre os visitantes que interagiram com alunos e docentes estão a francesa Pascale Mussard (diretora artística e fundadora da marca Petit $h$, do grupo Hermès), o mexicano Gustavo Garcia Villa (diretor de criação da revista L'Officiel México), as uruguaias Mariana Muzi e Magdalena Villaró (professoras de design de moda da Universidad ORT Uruguai), a paraguaia Adriana Chaparro (diretora da Associação de Confeccionistas do Paraguai) e a argentina Carolina Cenzano (docente do Instituto Nacional de Tecnologia Industrial da Argentina, setor Design). Ocasionalmente, alunos de moda da Belas Artes participaram como expositores do Salone Satellite, em Milão, ampliando a visibilidade da produção acadêmica, ao passo que docentes estrangeiros, como o professor turco Sakir Ozudogru, fizeram a opção de realizar estudos de campo de doutorado no Brasil por meio do grupo de estudos acadêmicos Design e Convergência, auspiciado pela Belas Artes. Todas essas ações foram acompanhadas por mentores externos: Waldick Jatobá, curador de arte e design, e

\footnotetext{
${ }^{3}$ Destacam-se nesse cenário três prêmios de desenvolvimento de uniformes para a companhia aérea TAM; prêmio de destaque no Concurso da loja de departamentos Renner em três anos consecutivos (2013, 2014 e 2015); prêmio de desenvolvimento de uniformes para o Vôlei de Praia do Banco do Brasil; Prêmio Cultural Qatar-Brasil, entre outros.
} 
Jorge Grimberg, jornalista da área, os quais, semanalmente, atenderam alunos e orientaram projetos, além de participar ativamente em sala de aula com palestras de atualização de repertório para o corpo docente e discente.

\subsubsection{Contexto de desenvolvimento do TCC}

Rankings internacionais de projeção institucional de escolas de design em ambiente global, como o QS World University Ranking by Subject, consideram como critérios avaliativos para a área de Design a reputação acadêmica, a reputação entre empregadores, a quantidade de citações de papers produzidos pelo corpo docente e discente e o impacto dos pesquisadores na comunidade acadêmica ( $\mathrm{H}$-index). Por outro lado, o relatório Warwick 2015, o qual analisa a educação superior na GrãBretanha, observa que a força e a diversidade do ecossistema da Economia Criativa dependem de uma educação ampla e balanceada, que desenvolve um largo espectro de caminhos para a criatividade profissional, com forte foco em uma vida cultural ativa, na sistematização de habilidades de comunicação e na pró-atividade e caráter empreendedor do estudante. Tal documento prevê que a empregabilidade de graduados com esse perfil deve crescer no âmbito da economia criativa britânica cerca, alcançando 67\% em torno de 2020 (WARWICK Report, 2015: 46). Já no relatório produzido pelo The Business of Fashion, website especializado em negócios da moda, Steve Pateman, head da unidade britânica do banco Santander, enfatiza como os estudantes de hoje necessitam de muitas habilidades novas para terem sucesso nas próximas décadas:

"eles precisam adquirir habilidades analíticas, focar em inteligência emocional, criatividade, inovação tanto quanto nas mudanças nos padrões de consumo... Treinar habilidades como comunicação e resolução de problemas são fundamentais para os futuros líderes" (BOF, 2015).

Como resultado dessas observações e discussões, conclui-se que o TCC em Design de Moda, sempre voltado ao bem-estar individual e coletivo, deve ser capaz de despertar a sensibilidade, estreitar relações e revelar caminhos inesperados para enfrentar desafios advindos da escassez de recursos, da contenção do consumo, da globalização econômica, da mundialização da cultura e do progresso tecnológico, entre outros. "Necessitamos de cientistas criativos tanto 
quanto de artistas que entendam as propriedades dos materiais e as potencialidades das novas tecnologias" (WARWICK Report, 2015: 45).

Assim, o Bacharelado em Design de Moda deve ensejar, como perfil desejado do formando, capacitação para a apropriação do pensamento reflexivo e da sensibilidade artística, para que o designer seja apto a produzir projetos que envolvam sistema de informações visuais, artísticas, estéticas culturais e tecnológicas, observados o ajustamento histórico, os traços culturais e de desenvolvimento das comunidades, bem como as características dos usuários e de seu contexto socioeconômico e cultural. Neste sentido, o Núcleo de Design do Centro Universitário Belas Artes de São Paulo convencionou que os procedimentos institucionais de elaboração de TCCs dos cursos de Design devem preservar a especificidade dos cursos, de modo a atingir os padrões de excelência definidos como meta para a internacionalização deste posicionamento.

A matriz curricular do curso de Design de Moda contempla disciplinas da área de humanidades, artes, tecnologia, design e moda a fim de garantir um profissional que conhece os princípios e fundamentos da comunicação, da linguagem, da arte e da sociedade, nos âmbitos culturais, econômicos e políticos. Além disso, fornece ao aluno o contato, desde o primeiro semestre, com disciplinas específicas da área profissional com o objetivo de estabelecer a conexão entre teoria e prática, promovendo um conhecimento profissional capaz de refletir constantemente sobre as repercussões de suas atividades. A cada semestre, o aluno realiza um projeto integrador multidisciplinar que permite exercitar práticas projetuais em Design de Moda, além de promover a habilidade para produzir conhecimento científico dentro dos padrões metodológicos da ABNT. Isso permite a familiarização do estudante com aspectos importantes para a realização do trabalho de conclusão de curso desde o primeiro semestre acadêmico.

Nesse sentido, cabe ao TCC contemplar dois aspectos altamente relevantes:

- Pesquisa aplicada em economia criativa: Fomentar a pesquisa acadêmica e a experimentação prática no desenvolvimento dos projetos, respaldando-os no estudo da teoria como vetor da reflexão e no empreendedorismo como fonte de inovação responsável. 
- Uso de recursos compartilhados: Incentivar o convívio social e o compartilhamento de recursos institucionais, incluindo laboratórios, estúdios e relações com o mercado, como assets no desenvolvimento de projetos.

Para estabelecer essas duas premissas, vários aspectos foram analisados, entre os quais os parâmetros de excelência acadêmica que levaram aos indicadores de performance. Para estabelecer tais padrões de qualidade, foram consultadas fontes de distintas naturezas: influenciadores da área de design, feiras internacionais, concursos internacionais, ranking de escolas de maior relevância global, empresas e acadêmicos, incluindo membros do corpo docente da Belas Artes e experts de outras universidades. Juntos, esses profissionais discutiram os indicadores de performance estabelecidos pelo BOF Global Survey, 2015, a saber: influência global (reputação global e influência da escola junto a recrutadores de empresas de prestígio para o trade de design); experiência de aprendizagem (satisfação dos alunos com o calibre dos colegas de curso, qualidade do corpo docente, energia das aulas e recursos disponibilizados pela instituição); valor de longo prazo (preparação do estudante para o "mundo real", acessando a satisfação do egresso quanto à empregabilidade, preparação para a carreira, ingresso na pósgraduação, validação de projetos por agentes de fomento e acesso a ex-alunos considerados bem-sucedidos).

\subsection{Metadesign nos princípios de organização do BA Creative Collectibles}

Visando a otimização de recursos e maior fluidez nos processos, o cronograma de entregas dos cursos de Design foi então unificado para todos os cursos do Núcleo de Design do Centro Universitário Belas Artes de São Paulo, incluindo o Bacharelado em Design de Moda. A unificação desses parâmetros permite que a apresentação de resultados dos TCCs elaborados por estudantes do Núcleo de Design ocorra simultaneamente, habilitando 0 formando ao estabelecimento de redes de relacionamento que apoiam o ingresso dos estudantes no mercado de trabalho por meio de exibição pública. Para tal, considera-se importante estabelecer um evento de apresentação misto dos TCCs de toda a área de Design, para público interno e externo. Este evento, denominado BA Creative Collectibles, é organizado e operacionalizado pela coordenação de curso com apoio dos departamentos de marketing, segurança e manutenção ao final de cada 
semestre letivo e consta de uma ocupação do campus que abriga os cursos de Design, do subsolo ao quinto andar do edifício.

O modelo de apresentação, iniciado no segundo semestre de 2016, foi estabelecido após seis meses de estudos e aprovado pelo Conselho Universitário (CONSU). Inicialmente, foi necessário construir um cronograma de trabalho, de modo a realizar o mapeamento dos espaços disponíveis no edifício, dividi-los em salas temáticas para facilitar o acesso segundo o interesse do visitante, e submeter ao Corpo de Bombeiros e Comissão de Ética para inspeção prévia, visando garantir a segurança dos participantes. Órgãos municipais, estaduais e federais, como Delegacia Regional de Educação, Agência Nacional de Vigilância Sanitária, Central de Engenharia de Tráfego, entre outros, também foram consultados. Paralelamente, foi preciso avaliar a capacidade da rede elétrica, as condições sanitárias dos projetos, a circulação do público, o processo de recepção e monitoria, bem como a distribuição, captação, organização e guarda dos documentos pertinentes à avaliação em si. Mas, certamente, o elemento mais desafiador foi o desenvolvimento de um equipamento de exibição (biombo e mesa) que permitisse abarcar projetos de naturezas distintas num espaço delimitado.

Figura 1 - Kits expositivos.

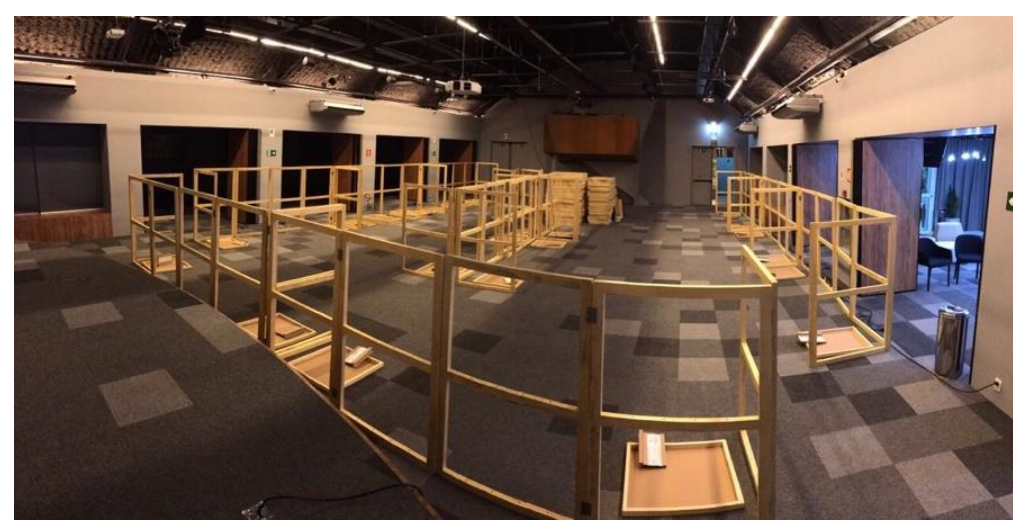

Fonte: Acervo da autora (2017)

Cada projeto recebe da instituição esse kit de exposição, que consta de biombo articulado e mesa expositora, no qual o autor apresenta seu trabalho. Esse equipamento permite ampla customização por parte do aluno, que elabora os princípios de apresentação de modo a captar a atenção do público visitante e eventualmente incorporar elementos procedentes dessa interação ao projeto, caracterizando a presença do metadesign. 
Assim, uma característica fundamental do projeto tradicional de design, que é ser tipicamente top-down, é subvertida no metadesign para ceder lugar a um processo de acompanhamento de processos emergentes no seio da comunidade que se forma ao redor do projeto. (ALÃO, 2015, p. 128).

A montagem e desmontagem dos estandes, assim como a recepção dos visitantes, é feita pelos próprios alunos, criando um sentido de engajamento no corpo discente. A etapa de montagem e desmontagem é de inteira responsabilidade dos autores dos projetos, que podem, a seu critério, convidar familiares e amigos para auxílio nesta fase. A instituição, por sua vez, disponibiliza a equipe de manutenção e o apoio do corpo docente. A rigor, a abertura se dá no período noturno do primeiro dia (das 19 às 21 horas), sendo seguida de horário de visitação diurna ininterrupta (das 10 às 16 horas) no dia seguinte.

Por outro lado, a recepção de visitantes, imprensa e avaliadores ocorre em sistema de monitoria voluntária, realizada por alunos de semestres anteriores, permitindo que estes se familiarizem com os procedimentos. Essa ação conta com o apoio da equipe de eventos e de marketing, além da supervisão da Coordenação do Ciclo de Conclusão, que supervisiona o BA Creative Collectibles. Todos esses processos preveem treinamentos prévios, realizados por docentes ligados ao Studio Grid (estúdio responsável pelas atividades complementares do Núcleo de Design) e pela coordenação do NEI - Núcleo de Empreendedorismo e Inovação da Belas Artes.

\subsubsection{Procedimentos de avaliação em exibição interativa}

Considerando o cenário descrito anteriormente, o TCC aplica de maneira congruente todo o conhecimento e repertório do aluno absorvido ao longo da graduação, tendo como resultado a sua produção intelectual apresentada por meio da pesquisa, do desenvolvimento e documentação do projeto no BA Creative Collectibles. Todavia, há que se observar que o sistema cíclico de avaliações é gradativamente substituído por avaliação processual e contínua, que ganha complexidade ao incluir agentes externos, como profissionais de mercado e público visitante.

Considerando tal cenário e os eixos estruturantes da matriz curricular, entende-se que, para alcançar a excelência, todo projeto de TCC da área de Design deverá compreender o levantamento do estado da arte das pesquisas acadêmicas 
acerca do tema de interesse do projeto, com seleção de autores e conceitos-chave para o desenvolvimento justificado da proposta, consolidando aportes científicos que forneçam adequado embasamento à aplicação prática do projeto. Igualmente, deverá promover a pesquisa e experimentação na essência da prática acadêmica de vanguarda. Como resultado, a construção e afirmação da identidade estética do projeto deve se dar por meio de viabilidade técnica indiscutível, assertividade mercadológica irrefutável e qualidade de acabamento impecável. A excelência acadêmica é alcançada no grau máximo quando da perfeita integração desses itens.

Ressalta-se que a apresentação pública no BA Creative Collectibles é apreciada por, no mínimo, três avaliadores, sendo um deles o orientador do projeto e dois expoentes da área de Design, seja em âmbito acadêmico ou profissional. Comumente, contudo, o estudante, ao apresentar seu projeto a centenas de visitantes, tem um laboratório vivo no contato e no intercâmbio de ideias, aprendendo enquanto apresenta o projeto de maneira orgânica e sem a pressão habitual produzida por apresentações para banca avaliadora em recinto fechado.

Os avaliadores são definidos pelo orientador do projeto, com supervisão da coordenação de curso, Núcleo Docente Estruturante e Colegiado de Curso sem o conhecimento prévio do estudante de quem será seu avaliador. O avaliador apresenta-se após a avaliação em si, o que permite um diálogo franco e aprofundado. Sua apreciação é documentada em ficha de avaliação própria, considerando os parâmetros destacados a seguir:

1. Ideia e conceito: avaliar de modo global o projeto e sua capacidade de se relacionar com o mercado brasileiro e internacional (itens: pertinência; relevância).

2. Potencial criativo e diferencial do projeto: avaliar a originalidade, a capacidade de inovação do projeto e o potencial do projeto de se encaixar nas demandas do mundo contemporâneo (itens: criatividade; potencial de inovação).

3. Capacidade de execução: avaliar como o projeto utiliza os recursos disponíveis no mercado brasileiro ou regional com excelência e se apresenta qualidade de execução compatível com o mercado ao qual se destina. Recursos, fornecedores, processos, matérias-primas e tecnologia devem ser levadas em consideração (itens: pesquisa e desenvolvimento; finalização e acabamento).

4. Impacto e engajamento: avaliar os benefícios do projeto considerando a inovação responsável, bem como o impacto no entorno e a capacidade de influenciar positivamente a comunidade na qual se insere. Considerar o pitch dos 
responsáveis: sua motivação, paixão e conhecimento amplo do tema ao falar do projeto (itens: orientação ao usuário; apresentação da proposta).

5. Viabilidade e projeção de crescimento: avaliar a possibilidade de acesso da proposta ao universo dos negócios e sua potencial projeção comercial (itens: aplicabilidade e exequibilidade; viabilidade econômica).

Destaca-se que cada parâmetro de avaliação soma 2,0 (pontos) a partir da consideração da realização de dois itens pré-definidos conforme acima. A atribuição de pontuação 1,0 (um) por item soma o total de 10,0 (dez) pontos por ficha de avaliação completa. A nota final considera peso 1 por cada ficha preenchida por avaliador convidado e peso 2 para a ficha preenchida pelo orientador do projeto, que consta da avaliação final in loco e da avaliação processual realizada nas fichas de acompanhamento de orientações. Além dos parâmetros quantitativos, cada avaliador dispõe de espaço para comentários e sugestões na ficha de avaliação. O público visitante, por sua vez, também poderá, a critério próprio, preencher ficha com comentários que não integram a nota final, mas expressam ao aluno o feedback dos visitantes acerca do TCC. Essa documentação, após apresentação ao aluno por ocasião da vista de notas, é arquivada pela instituição.

\subsubsection{Processo de difusão e visibilidade}

É importante salientar que o aluno recebe treinamento para seu pitch por meio de oficinas realizadas em conjunto com o coordenador do $\mathrm{NEI}$ - Núcleo de Empreendedorismo e Inovação da Belas Artes. Igualmente, é ofertado um media training em parceria com as assessorias de imprensa institucionais, que orientam o aluno em seu marketing pessoal e relacionamento com a imprensa, uma vez que este cria todo o processo de promoção de seu projeto nas mídias sociais. Essa ação permite um crescimento orgânico da visibilidade dos projetos, dado que os próprios alunos acionam suas redes de relacionamento e amplificam a exposição de seus colegas por meio de curtidas e reposts.

Os procedimentos de difusão do TCC são amplamente considerados nesse modelo de ciclo de conclusão de curso. A organização do memorial descritivo/storytelling do projeto, voltada à participação futura do egresso em feiras, concursos e showrooms, inclui a produção de um vídeo (com até um minuto de duração), narrativa imersiva, website ou aplicativo, passível de ser disponibilizado e 
divulgado por meio das mídias sociais digitais, além de texto em formato de press release com até 30 linhas para divulgação junto à imprensa e de mínimo de cinco a máximo de dez fotos em alta resolução (300 dpi) para divulgação junto à imprensa e mídias sociais digitais. Isso permite que as assessorias de imprensa institucionais organizem a divulgação dos projetos nos meios adequados.

Tais materiais são entregues em mídia digital com tag incluindo nome do aluno e do projeto, acompanhados de cópia de cessão de direitos de autor da equipe envolvida, como atores, fotógrafos, modelos e stylists em até dez dias antes da apresentação pública do projeto. Igualmente, a pasta digital conta com arquivo incluindo os créditos para todos os participantes do projeto, nominando claramente suas funções e participação no mesmo. O material é então encaminhado para inclusão no sistema de bibliotecas do Centro Universitário Belas Artes de São Paulo em formato digital, permitindo o compartilhamento dos resultados com a comunidade. Tais práticas, uma vez respaldadas como pilares institucionais, são consideradas como adjuntas no processo de construção de identidade e assinatura de design, tanto quanto de branding pessoal, do egresso da Belas Artes.

Cabe ainda ressaltar que, dentre os requisitos para aprovação final, é exigida a elaboração de um resumo científico e de um pôster científico, assinados em conjunto com o professor orientador, nos moldes acadêmicos demandados pelos principais eventos científicos realizados anualmente no Brasil, tendo como parâmetros propostos o Colóquio de Moda (Design de Moda) e o P\&D (Design Gráfico, Design de Interiores e Design de Produto). Esse documento é elaborado na disciplina TCC I e revisado na disciplina TCC II para entrega final em sintonia com os resultados obtidos na elaboração do projeto. A entrega da documentação nos prazos estabelecidos em cronograma e realização de todas as etapas previstas pelo orientador, incluindo projeto de stand para análise dos setores responsáveis, faz parte do processo de avaliação contínuo do projeto. Igualmente, a organização de stand para o BA Creative Collectibles, incluindo montagem e desmontagem nos prazos previstos no cronograma, bem como presença e atendimento ao público nos horários estipulados pela coordenação de curso, são elementos constitutivos do processo avaliativo. Isso permite ao estudante experimentar distintas fases da promoção de seu projeto. 


\subsection{Etapas de adequação ao modelo Collectibles}

Conforme mencionado anteriormente, o TCC inclui a elaboração do projeto, mas também a organização do portfólio individual no penúltimo e último semestre do curso. Os alunos desenvolvem seus projetos e portfólios de graduação refletindo sua personalidade e visão do design. Cada projeto deverá contemplar experiências investigativas, analíticas, formais, sensoriais e técnicas. No BA Creative Collectibles, o trabalho é avaliado por membros da academia e do mercado, sendo posteriormente considerado para envio a congressos e concursos de várias naturezas. A primeira etapa, desenvolvida na disciplina TCC I - Pesquisa e Concepção, está focada na conceituação do problema e é cursada em grupo. Neste semestre, o aluno conceitua o projeto e desenvolve a pesquisa científica e, no semestre subsequente, realiza os protótipos previstos e organiza a promoção do projeto. A elaboração conceitual voltada ao desenvolvimento de respostas criativas em design considera para a realização do TCC a recuperação das pesquisas acadêmicas realizadas pelo estudante nos projetos interdisciplinares elaborados semestralmente. A partir de uma seleção do estudante, há retomada e continuidade de projetos anteriores, conforme interesse e aderência do mesmo ao tema.

Os eixos temáticos considerados para a elaboração desta etapa do TCC correspondem aqueles adotados pelos principais eventos científicos da área de Design realizados anualmente no Brasil, notadamente o P\& D Design - Congresso Brasileiro de Pesquisa e Desenvolvimento em Design, maior evento na área do Design no país e o Colóquio de Moda, maior congresso científico de moda do Brasil, que possui uma área exclusiva para apresentação de resultados de TCCs, o Congresso de Iniciação Científica. Este se apresenta como espaço acadêmico para intercâmbio entre estudantes, pesquisadores e professores para promover reflexões, questionamentos, integração e relações entre as várias formas de abordagem da Moda e áreas afins, incluindo Design de Produto, Design Gráfico e Design de Interiores. A seleção destes eventos se dá por sua representatividade junto ao meio acadêmico, bem como pela adesão das temáticas abordadas à formação ofertada pelos quatro cursos de Design do Centro Universitário Belas Artes de São Paulo.

A disciplina TCC I - Pesquisa e Concepção é pré-requisito indispensável para cursar a disciplina TCC II - Projeto de graduação. Uma vez aprovado na disciplina TCC I - Pesquisa e Concepção, o estudante preenche uma ficha de 
seleção de orientador, na qual inclui seu tema e resumo científico, assim como aponta três possíveis orientadores para o projeto dentre os membros do corpo docente do Centro Universitário Belas Artes de São Paulo. Como parte das atividades da disciplina TCC I - Pesquisa e Concepção, os estudantes disponibilizam em ambiente digital o resumo científico, o pôster científico e um vídeo explicativo dos objetivos a serem alcançados pelo projeto, para consulta dos orientadores pretendidos, que então sinalizam sua predisposição ou não em aceitar a orientação do projeto. A partir do cruzamento dessas informações, a coordenação de cursos aponta o orientador do projeto, sempre dentro da seleção inicial dos estudantes.

A segunda etapa, desenvolvida na disciplina TCC II - Projeto de graduação, tem como objetivo a concretização da solução, com orientação individualizada. O objetivo da orientação de TCC é respaldar a elaboração de projetos de design focados em soluções criativas para demandas contemporâneas, cuja amplitude seja capaz de fortalecer as relações entre design, tecnologia, natureza e sociedade, compreendendo seu caráter híbrido e multidisciplinar no âmbito da economia criativa. A orientação de TCC é um componente essencial da experiência acadêmica na Belas Artes. Os professores orientadores trabalham junto aos estudantes para conceber um plano de ações que permita a todos alcançar seus objetivos educacionais. A interação entre orientadores e orientandos amplia os objetivos de ensino-aprendizagem da instituição além da sala de aula. Os orientadores devem informar os estudantes acerca de todos os aspectos (regimentais, legais, sociais e financeiros) que implicam cada decisão tomada no desenvolvimento do projeto, estimulando um ambiente intelectualmente ativo. Ao longo do desenvolvimento do TCC, os alunos podem encontrar uma variedade de fatores que afetem sua performance acadêmica e os orientadores devem estar aptos a resolver muitas dessas questões numa perspectiva de ampla atuação, dado seu conhecimento dos recursos institucionais, incluindo laboratórios, estúdios e biblioteca. Seu papel é direcionar seus orientandos ao melhor uso de tais recursos, otimizando um sistema de apoio. A atuação do orientador inclui também o provimento de informações assertivas sobre as políticas institucionais, criando um ambiente de apoio próprio não só para o desenvolvimento do TCC, como para a transformação responsável dos estudantes em profissionais que florescerão criativamente e intelectualmente. 
Para participar do BA Creative Collectibles, o aluno deverá, obrigatoriamente, desenvolver o TCC durante o último semestre do curso, atendendo às ementas previstas na disciplina e na atividade concernente ao Trabalho de Conclusão de Curso. Isso implica necessariamente em atender os requisitos estabelecidos na disciplina do semestre anterior, voltada à conceituação do projeto, conforme estabelecido em regulamento próprio integrante do Projeto Pedagógico de Curso (PPC). Antes do preparo para a exibição pública no BA Creative Collectibles, portanto, o TCC do curso de Bacharelado em Design de Moda do Centro Universitário Belas Artes de São Paulo deve considerar a elaboração de documentos científicos (resumo científico e pôster científico) para difusão do conhecimento, própria da economia de compartilhamento, em fóruns apropriados para tal, como colóquios, congressos, seminários, entre outros. Dessa feita, as atividades incluem elaboração de resumo e pôster científico nos moldes dos principais congressos brasileiros da área, realizados anualmente e com espaço para divulgação de TCCs. Isso é feito no penúltimo semestre do curso e a comunicação com a comunidade científica deverá contribuir com o posicionamento institucional nos rankings acadêmicos nacionais e internacionais, além de permitir a discussão prévia do projeto com pares de outras instituições de ensino.

Em termos específicos, espera-se que, com o TCC apresentado no Collectibles, o estudante apresente pleno domínio das seguintes competências:

- Construir filosofia de design própria em termos de expressão e conteúdo simbólico, com convicção advinda do conhecimento histórico tanto quanto das reflexões teóricas que balizam a cultura contemporânea.

- Afirmar contínuo comprometimento com o processo criativo por meio de forte reflexão intelectual e versatilidade requisitada para trabalhar em equipes híbridas e multidisciplinares.

- Desenhar, produzir e progressivamente apresentar criações cada vez mais coerentes, contemporâneas e autênticas.

- Expressar curiosidade sofisticada acerca de tecnologias e matérias-primas emergentes para elaboração de projetos, denotando profundo conhecimento de materiais e técnicas.

- Identificar e explorar problemas complexos para gerar soluções criativas incorporando todos os aspectos projetuais do design. 
- Contextualizar desafios e otimizar recursos na busca de soluções voltadas à inovação responsável.

- Conhecer padrões de excelência relativos às práticas sustentáveis, pesquisa de materiais, qualidade ambiental, estética, tecnologia e integração entre homem e espaço urbano.

- Promover a convergência entre design e pesquisa científica - do biodesign à internet das coisas - permitindo que os resultados tomem forma na vida cotidiana.

- Apresentar resultados em processos 2D e 3D, incluindo ficha técnica detalhada de materiais e acabamentos que permitem inovação em forma, volumetria, cortes e silhueta.

- Implementar sensibilidade estética por meio do domínio de técnicas digitais e analógicas, incluindo narrativas imersivas, para comunicar ideias e projetos.

- Demonstrar excepcional habilidade em construção e modelagem (prototipagem).

- Desenvolver visão humanística para as necessidades do usuário final em termos ergonômicos, estéticos, simbólicos, históricos e comerciais.

\section{CONCLUSÃO}

Hoje, a apresentação pública de resultados obtidos no TCC de Design de Moda do Centro Universitário Belas Artes de São Paulo é considerada por professores e estudantes como fundamental no incentivo ao processo de ensinoaprendizagem. Nesse sentido, três objetivos destacam-se: estímulo ao aluno no tocante ao empenho no desenvolvimento dos projetos; estabelecimento de network profissional para o egresso e reconhecimento de alumni; visibilidade do aluno e da instituição junto ao público externo (mídia, empresariado, academia, familiares do aluno, futuros alunos).

Graças ao êxito da experiência na área de Design, a terceira edição do BA Creative Collectibles, realizada em dezembro de 2017, incluiu todos os cursos de graduação da Belas Artes e expandiu suas ações para outros espaços urbanos, movimentando dez mil visitantes e mil e quinhentos avaliadores. Só na área de Design foram apresentados 220 projetos, incluindo coleções de vestuário, figurino, 
acessórios, fashion films, design têxtil, aplicativos, mobiliário, produtos eletrônicos, livros, entre outros. Já os cursos de Artes Visuais e Fotografia levaram suas produções ao Memorial da América Latina pelo período de um mês, alcançando a marca de sete mil visitantes, e possibilitando a comercialização das obras tanto para galerias quanto para consumidores finais.

Especificamente, podemos afirmar que o curso de Design de Moda da Belas Artes é parte do cenário de moda nacional e que o fortalecimento de sua imagem se deu por meio do BA Creative Collectibles. Por exemplo, Maísa Mariottini, formada em 2017, integrou o time de design da marca Isolda, do qual só saiu para criar sua marca própria. No mesmo ano, sua grife foi uma das selecionadas para integrar o grupo de egressos que representou a Belas Artes no showroom Blaiz, em Londres, durante a London Fashion Week. Além de Maísa Mariottini, participaram do evento seus colegas recém-formados Antônio Borges (marca homônima), Beatriz Barbosa Azevedo (WeMe), Gisele Faria e Ariadne Cordeiro (Kiru), com curadoria da expert internacional Simone Jordão. Heloísa Gomes, por duas vezes, representou a Belas Artes no Sallone Sattelite, sendo a primeira designer de moda convidada a apresentar vestidos no evento italiano, originalmente dedicado ao mobiliário, dada a qualidade de suas superfícies têxteis. Clayton Berini foi finalista do Prêmio Focus. Jéssica Sakawura, Marina Boaventura e Lívia Accorinte produziram coleções inspiracionais de estampas para a marca lorane, cujo lançamento ocorreu na Miami Design Week e a comercialização na loja da marca no Shopping Cidade Jardim, em São Paulo. Paralelamente, Thamires Smidi produziu coleções de estamparia botânica para a indústria têxtil Texprima, comercializadas em escala industrial.

A disseminação da cultura implementada pelo BA Creative Collectibles tornou-se ainda mais visível em 2018, por meio de parceria com o ecommerce Passarela, que comercializará as produções de alunos do quinto semestre, preparando-os para a elaboração do TCC com uma ampla visão de resultados comerciais de suas coleções. Essas oportunidades vieram à tona em virtude do cenário favorável criado pelo BA Creative Collectibles para aproximação entre instituição de ensino e empresas. A colocação dos projetos em contato com o usuário funciona para que haja um contínuo feedback, em sucessivas interações projetuais, que configuram uma diluição dos processos de avaliação tradicionais e, por vezes, afastados do cotidiano profissional. Nota-se que processos antes lineares 
tendem a ser repetidos em espiral, incluindo novos atores em ambientes de maior complexidade.

Considerando tal cenário, é possível compreender o impacto gerado pelo BA Creative Collectibles em vários âmbitos. Nota-se, por parte dos alunos, a ampliação do uso de recursos ofertados pela instituição, incluindo biblioteca, laboratórios e oficinas, time de TI, auxílio pedagógico e psicológico, núcleo de inovação e empreendedorismo e parcerias institucionais para a elaboração de projetos com acabamento impecável. Em termos de reputação, percebe-se que o cuidado com a qualidade dos trabalhos permite maior visibilidade da instituição, do corpo docente e dos egressos junto a influenciadores do segmento de design de moda e ampla presença nos meios de comunicação impressos, eletrônicos e digitais, além das redes sociais.

Esse aspecto impacta diretamente no desenvolvimento de carreiras, com ampliação da taxa de retorno de egressos para pós-graduação, amplo uso do serviço de gestão de carreiras e presença maciça em eventos de networking promovidos pela instituição. Tendo em vista o percentual de alumni empregada em até seis meses de egressa e a satisfação de ex-alunos com seu preparo para o mercado, nota-se também que o network entre ex-alunos passou a se estender inclusive junto aos estudantes em curso, que se beneficiam da presença constante dos egressos na instituição. Por fim, as premiações geradas pela presença de alunos e egressos finalistas nos maiores concursos do setor nos últimos anos propicia estímulo ao corpo docente, que busca aprimorar sua própria habilidade técnica, relações interpessoais e presença no mercado.

\section{REFERÊNCIAS}

ALÃO, Rui Sérgio Dias. Projeto e complexidade. Reflexões sobre um design colaborativo. Tese de Doutorado em Design e Arquitetura. FAUUSP, São Paulo, 2015.

ALSTYNE, Greg; LOGAN, Robert K. Designing for emergence and innovation: redesigning design. $2007 . \quad$ Disponível em: <http://www2.physics.utoronto.ca/ logan/VanAlstyneLoganFinal.doc>. Acesso em: 31 de março de 2018, 16:30. 
ASSOCIAÇÃO Brasileira da Indústria Têxtil e de Confecção, 2018. Perfil do setor. Disponível em <http://www.abit.org.br/cont/perfil-do-setor>. ABIT. Acesso em 29 de março de 2018, 12:00.

BOTSMAN, Rachel; ROGERS, Roo. O que é Meu é Seu: Como o consumo colaborativo vai mudar o nosso mundo. Porto Alegre: Bookman, 2011.

CORNER, Frances. 2015. Schools Must Respond to the Needs of the Industry. Disponível em <https://www.businessoffashion.com/community/voices/discussions/how-shouldfashion-schools-integrate-business-learning-into-a-creative-education/op-ed-schoolsmust-respond-to-the-needs-of-the-industry>. The Business of Fashion Education Report 2015. Acesso em 30 de março de 2018, 11:14.

DE WAAL, Martin. The city as interface. How new media are changing the city. Amsterdam: Naio10publishers, 2014.

FLORIDA, Richard. A Ascensão da Classe Criativa. Porto Alegre: L\&PM Editores, 2011.

GANSKY, Lisa. Mesh: Por que o Futuro dos Negócios é Compartilhar. Rio de Janeiro: Atlas Books, 2011.

HUGHES, Philip. Diseño de exposiciones. Londres: Lawrence King Publishing, 2010.

JENKINS, Henry. Cultura da Convergência. 2ª ed. São Paulo: Aleph, 2009.

QS. World University Ranking by Subject, 2017. Disponível em $<$ https://www.topuniversities.com/subject-rankings/2017>. Acesso em 11 de fevereiro de 2018, 18:30.

THALER, Richard; SUSSTEIN, Cassie. Nudge - O Empurrão para a Escolha Certa. Rio de Janeiro: Elsevier, 2009.

WARWICK Report, 2015. Enriching Britain: Culture, Creativity and Growth. The 2015 Report by the Warwick Commission on the Future of Cultural Value. [pdf]. Warwick University. Disponível em $<$ https://warwick.ac.uk/research/warwickcommission/futureculture/finalreport/warwick _commission_report_2015.pdf>. Acesso em 13 de fevereiro de 2018, 08:30. 